SANTOS, F.R. et al. Qualidade e composição nutricional de ovos convencionais e caipiras comercializados em Rio Verde, Goiás. PUBVET, Londrina, V. 5, N. 35, Ed. 182, Art. 1228, 2011.

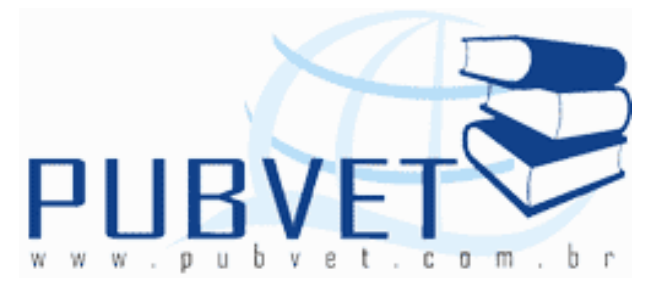

PUBVET, Publicações em Medicina Veterinária e Zootecnia.

\title{
Qualidade e composição nutricional de ovos convencionais e caipiras comercializados em Rio Verde, Goiás
}

\begin{abstract}
Fabiana Ramos dos Santos ${ }^{1 *}$, Lívia da Cunha Moreira Pereira ${ }^{1}$, Cibele da Silva Minafra ${ }^{1}$, Priscila Alonso dos Santos ${ }^{1}$, Andrea Luciana dos Santos ${ }^{2}$, Paula Rodrigues Oliveira ${ }^{1}$
\end{abstract}

${ }^{*}$ Endereço para correspondência: ${ }^{1}$ Instituto Federal Goiano - Campus Rio Verde. Rodovia Sul Goiana, Km 01, Caixa Postal 66, Zona Rural, CEP - 75.901040, Rio Verde - GO, Brasil. Tel. (64) 3620-5618, e-mail: framosantos@yahoo.com.br

${ }^{2}$ Departamento de Zootecnia, Universidade Federal de Mato Grosso - Campus de Rondonópolis, Rodovia Rondonópolis-Guiratinga (MT-270), Km 06, Bairro Sagrada Família, CEP - 78735-910 Rondonópolis - MT

\section{Resumo}

O trabalho teve por objetivo avaliar a qualidade interna, externa, microbiológica, os níveis de colesterol na gema e a composição centesimal de ovos convencionais (ovo de casca branca e marrom) e caipiras comercializados em Rio Verde, Goiás. Os ovos foram adquiridos em diferentes estabelecimentos comerciais da cidade de Rio Verde ao acaso, sem observar a data de validade do produto e simulando a escolha do consumidor. Os ovos caipiras apresentaram melhor qualidade interna que os ovos convencionais, refletida principalmente no melhor valor de unidade Haugh $(p>0,05)$. Não 
SANTOS, F.R. et al. Qualidade e composição nutricional de ovos convencionais e caipiras comercializados em Rio Verde, Goiás. PUBVET, Londrina, V. 5, N. 35, Ed. 182, Art. 1228, 2011.

ocorreu crescimento microbiano de coliformes totais e fecais em nenhum dos tratamentos. Quanto à composição centesimal os percentuais de cinzas, umidade e extrato etéreo não diferiram entre si $(p>0,05)$. Os teores de proteína foram diferentes entre os tratamentos, sendo maior valor o dos ovos convencionais marrons. Não houve diferença entre os tratamentos quanto aos níveis de colesterol na gema. Conclui-se os ovos caipiras apresentam melhor qualidade interna, porém, não existem diferenças significativas quanto aos níveis nutricionais e microbiológicos entre os diferentes tipos de ovos.

Palavras-chave: galinhas caipiras, qualidade, ovos.

\title{
Quality nutritional composition of conventional and organic eggs marketed in Rio Verde, Goiás
}

\begin{abstract}
The objective of the research were evaluate the internal quality, external, microbiological, levels of cholesterol in the yolk and nutrients composition of conventional (shell white and brown) and organic eggs marketed in Rio Verde, Goiás. The eggs were obteined randomly at different supermarkets in the city of Rio Verde, without observing the expiration date of the product and simulated consumer choice. The organic eggs were better internal quality than the conventional eggs, reflected mainly in the optimum value of unit Haugh $(p>0.05)$. No occurred microbial growth in total and fecal coliforms in any treatment. The percentage composition of ash, moisture and ether extract did not differ $(p>0.05)$. The protein contents were different between treatments, however, the higher value was observed in conventional brown eggs. There was no difference between treatments in the levels of cholesterol in the yolk $(p>0.05)$. It is the organic eggs have better internal quality, however, no significant differences for microbiological and nutritional levels among the different eggs.
\end{abstract}

Keywords. eggs, quality, organic chickens. 
SANTOS, F.R. et al. Qualidade e composição nutricional de ovos convencionais e caipiras comercializados em Rio Verde, Goiás. PUBVET, Londrina, V. 5, N. 35, Ed. 182, Art. 1228, 2011.

\section{INTRODUÇÃO}

O ovo comercial é produto da eficiente transformação biológica feita pela poedeira. Essa ave transforma recursos alimentares de menor valor biológico em produto com alta qualidade nutricional para o consumo humano.

Apesar das inúmeras características nutricionais positivas dos ovos, de acordo com ANDRADE, (2005) muitas vezes estes são indicados como veiculadores de bactérias, que são responsáveis por inúmeras intoxicações alimentares.

A composição e a qualidade do ovo depende de fatores biológicos relacionados à fisiologia da galinha, sendo influenciada, ainda, pelo aporte nutricional, práticas de manejo e ambiente adequados a sua criação (BERTECHINI, 2003).

Atualmente é crescente a demanda por produtos do tipo caipira ou orgânico no mercado e isto é justificado pelo fato das pessoas buscarem a cada dia produtos naturais, supostamente mais saudáveis e produzidos em sistemas menos intensivos com o mínimo estresse para os animais (FANATICO, 2008). Estes consumidores buscam o ovo caipira pelo fato destes apresentarem características como sabor, coloração e qualidade nutricional que acreditam ser diferenciados em relação ao sistema convencional.

No sistema caipira de criação, diferente do que ocorre no sistema convencional em gaiolas, as aves ficam em contato direto com os ovos nos ninhos. Assim, este sistema de criação pode favorecer uma maior contaminação, uma pior qualidade interna dos ovos produzidos e um eminente risco à saúde dos consumidores.

O presente trabalho teve por objetivo avaliar a qualidade interna, externa, microbiológica e os níveis de colesterol na gema de ovos convencionais (ovo de casca branca e marrom) e caipiras comercializados em Rio Verde, Goiás. 
SANTOS, F.R. et al. Qualidade e composição nutricional de ovos convencionais e caipiras comercializados em Rio Verde, Goiás. PUBVET, Londrina, V. 5, N. 35, Ed. 182, Art. 1228, 2011.

\section{MATERIAL E MÉTODOS}

\section{Coleta das amostras}

Foram analisados ovos convencionais (cascas brancas e marrons) e ovos caipiras. Os ovos foram adquiridos em diferentes estabelecimentos comerciais da cidade de Rio Verde ao acaso, sem observar a data de validade do produto e simulando a escolha do consumidor.

As análises foram realizadas em duas etapas: durante a primeira etapa foram realizadas as análises de qualidade externa, interna, mensuração dos níveis de colesterol da gema e análise microbiológica. Na segunda etapa foi determinada a composição centesimal dos nutrientes dos ovos.

Todas as análises foram realizadas nos laboratórios de bromatologia, bioquímica e metabolismo animal e microbiologia do Instituto Federal de Educação, Ciência e Tecnologia Goiano - Campus Rio Verde.

\section{Análise da qualidade externa e interna dos ovos}

Para avaliar a qualidade externa e interna dos ovos foram mensurados os parâmetros: integridade das casas, peso dos ovos, gravidade específica, coloração de gema, unidades Haugh, constituição percentual de casca, gema e albume.

A integridade da casca foi mensurada através da observação de todos os ovos (trincados, sujos e quebrados), peso do ovo (percentagem de ovos fora do padrão (ovos com peso inferior a $55 \mathrm{~g}$, o estabelecido pela legislação, BRASIL, (1965) - Decreto $n^{\circ} 56.585$, de 20 de julho de 1965) e gravidade específica.

Para a determinação do peso dos ovos, estes foram mensurados individualmente em balança de precisão de 0,01 grama. Para determinar a gravidade específica, os ovos foram imersos em soluções salinas com densidades que variam de 1,060 a 1,100 com aumento de 0,005 medidos com densímetro de petróleo. Esta técnica considera a densidade do ovo a solução na qual este flutua. 
SANTOS, F.R. et al. Qualidade e composição nutricional de ovos convencionais e caipiras comercializados em Rio Verde, Goiás. PUBVET, Londrina, V. 5, N. 35, Ed. 182, Art. 1228, 2011.

As análises de qualidade interna realizadas foram: unidade Haugh, índice de gema, coloração de gema e altura de albume e constituintes percentuais de gema, albume e casca.

Para avaliação interna foram utilizados os seguintes procedimentos: o ovo foi quebrado em uma superfície plana e lisa. Foi medida a altura do albume denso, da gema e o diâmetro da gema com um paquímetro.

A colorimetria de gema, analisada visualmente com auxílio de um leque colorimétrico DSM ${ }^{\circledR}$. Nesta análise, foi comparada a cor da gema, sobre um fundo branco, com a escala de coloração do leque e determinada a pontuação descrita no mesmo.

Para finalizar, a gema foi separada do albume e pesada.

As cascas dos ovos foram identificadas, lavadas, permaneceram em estufa a $105^{\circ} \mathrm{C}$ por duas horas e depois foram pesadas em balança de precisão de 0,01 grama. O peso do ovo com a casca foi subtraído do peso da gema e da casca, que resultou no peso do albume, e assim se calculou o percentual de gema, casca e albume.

A unidade Haugh foi calculada utilizando-se a seguinte fórmula: UH = $100 \log (\mathrm{h}-1,7 \mathrm{P} * 0,37+7,6)$, em que $\mathrm{h}=$ altura de albume denso $(\mathrm{mm})$ e $\mathrm{p}=$ peso do ovo $(\mathrm{g})$.

O índice de gema foi calculado pela fórmula: IG = altura da gema $(\mathrm{mm})$ / diâmetro da gema (mm).

\section{Contagem de coliformes fecais e totais e composição nutricional dos ovos}

Para a determinação dos níveis de colesterol na gema, análises microbiológicas e composição centesimal dos ovos foi realizado um pool do conteúdo de três ovos por repetição.

Para mensurar a contaminação dos ovos foram realizadas análises microbiológicas com o objetivo de identificar o número mais provável (NMP) de coliformes totais e fecais. A metodologia foi seguida de acordo com as técnicas descritas por SILVA (1997). 
SANTOS, F.R. et al. Qualidade e composição nutricional de ovos convencionais e caipiras comercializados em Rio Verde, Goiás. PUBVET, Londrina, V. 5, N. 35, Ed. 182, Art. 1228, 2011.

Quanto à composição centesimal as variáveis analisadas foram: matéria seca, proteína bruta, extrato etéreo, cinzas e extrativo não nitrogenado. As amostras foram congeladas e as análises de matéria seca, cinzas e proteína bruta foram realizadas conforme os procedimentos descritos por SILVA \& QUEIROZ, (2002).

\section{Análises Estatísticas}

O delineamento experimental utilizado foi o inteiramente casualizado com três tratamentos (ovos caipiras, convencionais de casca branca e convencionais de casca marrom) e seis repetições de doze ovos cada.

Os dados coletados foram submetidos à análise de variância. Para comparação das médias entre os tratamentos, foi utilizado o teste de Tukey a um nível de significância de $5 \%$. As análises estatísticas foram realizadas por meio do Software SISVAR (FERREIRA, 2003).

\section{RESULTADOS E DISCUSSÃO}

$\mathrm{Na}$ Tabela 1 estão apresentados os dados de percentual de ovos anormais de ovos caipiras e convencionais.

Tabela 1. Porcentagem de ovos anormais (sujos, trincados e quebrados) de ovos caipiras e convencionais

\begin{tabular}{llc}
\hline Tipos de ovos & Ovos sujos & Ovos trincados e quebrados \\
\hline Caipira & 69,08 & 0,70 \\
Marrom & 36,92 & 2,82 \\
Branco & 41,92 & 4,93 \\
CV(\%) & 40,50 & 50,55 \\
\hline
\end{tabular}

Em função do elevado coeficiente de variação, não houve diferenças estatísticas entre os tipos de ovos para a anormalidade de ovos $(p>0,05)$. Os ovos caipiras apresentaram numericamente maior percentual de ovos sujos, fato que era esperado pelo ambiente de criação das aves e pelo fato da 
SANTOS, F.R. et al. Qualidade e composição nutricional de ovos convencionais e caipiras comercializados em Rio Verde, Goiás. PUBVET, Londrina, V. 5, N. 35, Ed. 182, Art. 1228, 2011.

postura ser realizada em ninhos, o que favorece o maior contato com sujidades e excretas. A contaminação externa da casca do ovo é importante para determinação de sua vida-de-prateleira e para a segurança dos consumidores (SCHOENI, 1995). Isso ocorre pelo fato das sujidades nos ovos depreciarem o produto e por aumentar a probabilidade de contaminação bacteriana (LEANDRO, 2005).

Em números absolutos, os ovos convencionais apresentaram um maior percentual de ovos trincados, o que pode ser resultado do transporte e armazenamento inadequado deste produto. De acordo com ITO, (2007), a porcentagem de trincas nos ovos é aumentada em até $8,57 \%$ de acordo com o empilhamento das caixas no local de comercialização. O autor relata que caixas de ovos localizadas no topo da pilha apresentam 5,32\% de trincas e as localizadas na base, 13,89\%.

$\mathrm{Na}$ Tabela 2 estão apresentadas os pesos absolutos ( $\mathrm{g}$ ) e relativos (\%) dos constituintes de ovos caipiras e convencionais.

Tabela 2. Peso absoluto do ovo e peso de seus constituintes em gramas de ovos caipiras e convencionais

\begin{tabular}{lllll}
\hline Tipos de ovos & Ovos & Albume & Gema & Casca \\
\hline \multicolumn{5}{l}{ Peso absoluto, g } \\
\hline Caipira & $48,49 \mathrm{~b}$ & $27,75 \mathrm{~b}$ & $16,22 \mathrm{a}$ & $4,51 \mathrm{~b}$ \\
Marrom & $58,29 \mathrm{a}$ & $35,95 \mathrm{a}$ & $16,51 \mathrm{a}$ & $5,83 \mathrm{a}$ \\
Branco & $56,83 \mathrm{a}$ & $34,16 \mathrm{a}$ & $17,32 \mathrm{a}$ & $5,64 \mathrm{a}$ \\
CV(\%) & 4,99 & 10,09 & 7,86 & 7,00 \\
& Peso Relativo, \% \\
Caipira & $57,05 \mathrm{a}$ & $33,66 \mathrm{a}$ & $9,27 \mathrm{a}$ \\
Marrom & $51,66 \mathrm{a}$ & $28,33 \mathrm{~b}$ & $10,00 \mathrm{a}$ \\
Branco & $50,18 \mathrm{a}$ & $30,37 \mathrm{ab}$ & $9,44 \mathrm{a}$ \\
CV(\%) & 5,07 & 4,92 & 7,45
\end{tabular}

Médias com letras distintas na coluna diferem pelo teste de Tukey $(p<0,05)$ 
SANTOS, F.R. et al. Qualidade e composição nutricional de ovos convencionais e caipiras comercializados em Rio Verde, Goiás. PUBVET, Londrina, V. 5, N. 35, Ed. 182, Art. 1228, 2011.

Com relação ao peso absoluto, houve diferença significativa $(p<0,05)$ entre o peso do ovo caipira e os ovos convencionais. Os ovos caipiras foram mais leves que os convencionais.

É possível que o menor peso médio dos ovos caipiras pode ser atribuído ao fato destes serem comercializados sem que haja uma classificação por peso. Este problema não ocorre nos ovos industriais, uma vez que para a comercialização há uma maior preocupação por parte da indústria no atendimento da legislação vigente.

Os ovos convencionais analisados eram classificados como ovos grandes, ou seja, deveriam ter peso entre 55 e $60 \mathrm{~g}$, de acordo com BRASIL, (1965), o que foi confirmado na pesagem dos mesmos.

Não houve diferenças entre os tratamentos para o peso de gema e casca $(p>0,05)$.Os ovos convencionais apresentaram maior peso de albume em relação aos caipiras.

Os percentuais de albume e casca não apresentaram diferença significativa $(p>0,05)$ entre os tratamentos. Com relação à percentagem de gema foi observado maiores valores nos ovos caipiras, enquanto que os ovos marrons apresentaram o menor percentual $(p<0,05)$.

Vários fatores podem influenciar a constituição do ovo, dentre eles podem-se citar: tamanho do ovo, idade, alimentação, estado sanitário das aves, etc.

Na Tabela 3 estão apresentados os dados de gravidade específica, unidade Haugh, índice de gema e cor de gema de ovos caipiras e convencionais.

As variáveis gravidade específica e índice de gema não apresentaram diferença significativa entre os tratamentos $(p>0,05)$. 
SANTOS, F.R. et al. Qualidade e composição nutricional de ovos convencionais e caipiras comercializados em Rio Verde, Goiás. PUBVET, Londrina, V. 5, N. 35, Ed. 182, Art. 1228, 2011.

Tabela 3. Gravidade específica, unidade Haugh, cor de gema, índice de gema e cor de gema de ovos caipiras e convencionais

\begin{tabular}{lllll}
\hline Tipos de ovos & $\begin{array}{l}\text { Gravidade } \\
\text { específica }\end{array}$ & $\begin{array}{l}\text { Unidade } \\
\text { Haugh }\end{array}$ & $\begin{array}{l}\text { Índice } \\
\text { gema }\end{array}$ & $\begin{array}{l}\text { de } \\
\text { Cor } \\
\text { de gema }\end{array}$ \\
\hline Caipira & $1,071 \mathrm{a}$ & $74,29 \mathrm{a}$ & $0,39 \mathrm{a}$ & $10,19 \mathrm{a}$ \\
Marrom & $1,071 \mathrm{a}$ & $60,41 \mathrm{~b}$ & $0,36 \mathrm{a}$ & $3,72 \mathrm{~b}$ \\
Branco & $1,068 \mathrm{a}$ & $61,72 \mathrm{~b}$ & $0,38 \mathrm{a}$ & $3,72 \mathrm{~b}$ \\
CV(\%) & 0,83 & 7,12 & 7,51 & 8,03
\end{tabular}

Médias com letras distintas na coluna diferem pelo teste de Tukey $(p<0,05)$

Segundo SILVA, (2004), a densidade dos ovos não pode ser inferior a 1,080 . Todos os tratamentos apresentaram valores inferiores, indicando que os ovos analisados não foram de boa qualidade se considerarmos somente este parâmetro. Valores baixos de gravidade específica podem ser explicados pela forma de armazenamento do produto nos estabelecimentos comerciais.

Com relação ao índice de gema, os valores encontrados estão normais $(0,3$ a 0,5$)$.

Os ovos caipiras apresentaram valores de unidade Haugh superiores aos obtidos com ovos convencionais de casca marrom e branca $(p<0,05)$.

A melhor unidade Haugh dos ovos caipiras pode ser explicada pela maior rotatividade deste produto no mercado. Em virtude da menor oferta, os ovos caipiras são comercializados mais rapidamente que os convencionais. De acordo com BARBOSA, (2008) maiores tempos de armazenamento do produto em ambientes sem controle de temperatura e umidade favorecem a redução destes valores.

Considerando os valores de unidade Haugh dos ovos analisados é possível com os dados deste ensaio classificar os ovos caipiras como ovos tipo AA e os convencionais como ovos tipo A, uma vez que segundo SILVA, (2004) este parâmetro classifica os ovos em tipo AA (100 até 72), A (71 até 60), B 
SANTOS, F.R. et al. Qualidade e composição nutricional de ovos convencionais e caipiras comercializados em Rio Verde, Goiás. PUBVET, Londrina, V. 5, N. 35, Ed. 182, Art. 1228, 2011.

(59 até 30), C (29 até 0). É importante ressaltar que quanto maiores os valores da unidade Haugh, melhor é a qualidade do ovo.

Com relação à variável cor de gema o ovo caipira foi estatisticamente diferente $(p<0,05)$ dos ovos convencionais, sendo o ovo caipira o que apresentou a gema com maior coloração. Este resultado era esperado, devido à maior quantidade de xantofilas na dieta das aves caipiras. Os carotenóis influenciam na cor da gema e podem ter origens naturais, como o milho e o pimentão, ou origem sintética, como a cantaxantina $10 \%$ e o etil beta apo-8caroteno (BISCARO \& BRAZACA, 2006).

As galinhas caipiras por serem criadas soltas tem uma alimentação bastante variada, ingerindo vegetais, milho, etc; que são alimentos muito ricos em carotenos, proporcionando assim ovos com gemas mais amarelas que os das aves confinadas que muitas vezes recebem alimentação com baixos teores de pigmentos.

No que se refere à microbiologia, não foi observado crescimento de coliformes fecais e totais em todos os tratamentos avaliados (contaminação menor que 3,0 NMP/mL). Este resultado não eram esperados levando-se em consideração a grande presença de sujidades na casca de ovos caipiras. A ausência de contaminação com coliformes no conteúdo dos ovos pode ser justificada pela barreira de proteção exercida pela casca, o que provavelmente impediu a entrada dos microrganismos.

Resultados diferentes dos encontrados neste ensaio foram observados por CARDOSO, (2001) que analisando ovos comerciais de vários fornecedores em Descalvado São Paulo encontraram amostras positivas para coliformes fecais e totais, ambas com resultados entre o índice de 100 a 500 NMP de coliformes fecais/g.

Na Tabela 4 estão apresentados os dados de composição centesimal e níveis de colesterol $(\mathrm{mg} / \mathrm{g})$ de ovos caipiras e convencionais.

Não houve diferenças significativas entre os tratamentos com relação aos valores de porcentagem de umidade, cinzas e extrato etéreo $(p>0,05)$. 0 teor 
SANTOS, F.R. et al. Qualidade e composição nutricional de ovos convencionais e caipiras comercializados em Rio Verde, Goiás. PUBVET, Londrina, V. 5, N. 35, Ed. 182, Art. 1228, 2011.

de proteína bruta apresentou diferença estatística entre os tratamentos $(p<0,05)$. O maior valor foi encontrado no ovo convencional de casca marrom.

Tabela 4. Composição centesimal e níveis de colesterol $(\mathrm{mg} / \mathrm{g}) \mathrm{de}$ ovos caipiras e convencionais.

\begin{tabular}{lllllll}
\hline $\begin{array}{l}\text { Tipos de } \\
\text { ovos }\end{array}$ & $\begin{array}{l}\text { Umidade, } \\
\%\end{array}$ & Cinzas, \% & PB,\% & EE,\% & ENN,\% & $\begin{array}{l}\text { Colesterol } \\
(\mathrm{mg} / \mathrm{g})\end{array}$ \\
\hline Caipira & $73,05 \mathrm{a}$ & $0,95 \mathrm{a}$ & $12,79 \mathrm{~b}$ & $11,22 \mathrm{a}$ & $1,97 \mathrm{a}$ & $16,88 \mathrm{a}$ \\
Marrom & $72,61 \mathrm{a}$ & $1,01 \mathrm{a}$ & $13,73 \mathrm{a}$ & $10,77 \mathrm{a}$ & $1,85 \mathrm{a}$ & $16,76 \mathrm{a}$ \\
Branco & $73,25 \mathrm{a}$ & $1,02 \mathrm{a}$ & $12,82 \mathrm{~b}$ & $10,68 \mathrm{a}$ & $2,22 \mathrm{a}$ & $15,36 \mathrm{a}$ \\
CV(\%) & 2,07 & 13,14 & 4,07 & 7,99 & & 22,16 \\
\hline
\end{tabular}

Médias com letras distintas na coluna diferem pelo teste de Tukey $(p<0,05)$

MIZUMOTO, (2008) avaliaram ovos obtidos pela forma tradicional, semiorgânica, orgânica e também observaram diferenças entre os percentuais de proteína bruta. Porém neste ensaio, os maiores valores foram observados em ovos com cultivo convencional vermelho $(10,21 \%)$, orgânico $(10,86 \%)$ e semiorgânico $(10,72 \%)$ relação ao convencional branco $(9,04 \%)$. Diferenças entre o teor protéico podem ocorrer devido a fatores como idade da poedeira ou diferença de ração utilizada.

Com relação aos níveis de colesterol na gema não houve diferença entre os tratamentos, este resultado corrobora com os observados por OLIVEIRA, (2004) e SALVADOR \& DALLA SANTA, (2002) que não observaram diferenças quanto aos teores de colesterol de ovos de diferentes espécies de aves e tipos comerciais. Porém, os resultados diferem dos encontrados por SILVA, (2010) que verificaram uma grande diferença nos valores deste nutriente, não só entre ovos caipiras e granjeiros, mas também entre diferentes tipos caipiras (casca azul e casca marrom). 
SANTOS, F.R. et al. Qualidade e composição nutricional de ovos convencionais e caipiras comercializados em Rio Verde, Goiás. PUBVET, Londrina, V. 5, N. 35, Ed. 182, Art. 1228, 2011.

Teores de colesterol semelhantes aos deste estudo foram observados por MIZUMOTO (2006) que encontraram para ovos convencionais brancos $16,27 \mathrm{mg} / \mathrm{g}$ de colesterol na gema. Para ovos de casca vermelha o mesmo autor encontrou valores de $13,68 \mathrm{mg} / \mathrm{g}$ de colesterol na gema. HARDER, (2005) encontrou teor de colesterol de 10,41 a 16,95 mg/g de gema, para ovos obtidos com adição de urucum, (0,5 a $2 \%)$ sendo que a adição de urucum diminuiu o teor do mesmo.

Os teores de colesterol nos ovos podem ser alterados por meio de mudanças na dieta das aves, como por exemplo, através da inclusão de óleos ricos em ácidos graxos poliinsaturados na ração. MURATA, (2003) estudando os níveis de colesterol total na gema de ovo, utilizando diferentes fontes de óleo, verificaram que o colesterol da gema foi afetado pela fonte de óleo $(p<$ $0,05)$ com baixos valores quando o óleo de soja foi adicionado à dieta. Já SANTOS, (2005) adicionando nas dietas teores de 2 e $4 \%$ de diferentes óleos vegetais não observou alteração nos teores de colesterol dos ovos.

\section{CONCLUSÃO}

Conclui-se que a rápida rotatividade dos ovos caipiras no mercado de Rio Verde, Goiás proporciona á estes melhor qualidade interna em relação aos ovos convencionais que precisam passar por um maior tempo, entre o processo de industrialização e transporte, até chegar aos pontos comerciais. Porém, no que se refere ao valor nutricional, com exceção ao teor protéico, não foi identificada neste ensaio, diferenças significativas quanto aos níveis de nutrientes e ao número de coliformes totais e fecais entre os diferentes tipos de ovos.

\section{REFERÊNCIAS}

1. Andrade, MA, Café, MB, Jayme, VS, Rocha, PT, MogycA, NSL, Stringhini, JH. Avaliação da qualidade bacteriológica de ovos de galinha comercializados em Goiânia, Goiás, Brasil. Ciência Animal Brasileira. 2005; 5(4): 221-8. 
2. Barbosa, NAA, Sakomura, NK, Mendonça, MO, Freitas, ER, Fernandes, JBK. Qualidade de ovos comerciais provenientes de poedeiras Comerciais armazenados sob diferentes tempos e Condições de ambientes. Ars Veterinária. 2008; 24(2): 127-33.

3. Bertechini, A.G.. Mitos e verdades sobre o ovo de consumo. Conferência apinco de ciência e tecnologia avícolas. 2003. Campinas. Anais... Campinas: 2003. Página 19.

4. Biscaro, LM, Brazaca, SGC. Cor, betacaroteno e colesterol em gema de ovos obtidos de poedeiras que receberam diferentes dietas. Ciência e Agrotecnologia. 2006; 30(6):1130-4.

5. Brasil. Decreto $n^{\circ} 56.585$, de 20 de julho de 1965. Aprova as novas especificações a classificacao e fiscalizacao do Ovo. Diário Oficial [da] República Federativa do Brasil, Brasília, DF, 22 jul. 1965. Seção 1, Página 2.

6. Cardoso, ALSP, Tessari, ENC, Castro AGM, Kanashir OAM, Gama, NMSQ. Pesquisa de Coliformes Totais e Coliformes Fecais Analisados em Ovos Comerciais no Laboratório de Patologia Avícola de Descalvado, Arquivos do Instituto Biológico. 2001; 68(1): 19-22.

7. Fanatico, AC, Pillai, PB, Hester, PY, Falcone, C, Mench, JA, Owens, CM, Emmert, JL. Performance, livability, and carcass yield of slow- and fast-growing chicken genotypes fed low-nutrient or standard diets and raised indoors or with outdoor access. Poultry Science. 2008; 87(3):1012-21.

8. Ferreira DF. Sisvar: versão 4.3 (Build 43). Lavras: Departamento de Ciências Exatas: Universidade Federal de Lavras; 2003.

9. Harder, MNC. Efeito do urucum (Bixa orellana) na alteração de características de ovos de galinhas poedeiras. [Dissertação de Mestrado]. Piracicaba, São Paulo: Escola Superior de Agricultura Luiz de Queiroz, 2005. 74 pp.

10. Ito, DT. Como agregar valor ao ovo: pós produção. In: Curso de atualização em avicultura para postura comercial. 2007. Jaboticabal. Anais... Jaboticabal: Unesp. 10712.

11. Leandro, NSM, Deus, HAB, Stringhini, JH, Café, MB, Andrade, MA, CARVALHO, FB. Aspectos de qualidade interna e externa de ovos comercializados em diferentes estabelecimentos na região de Goiânia. Ciência Animal Brasileira. 2005; 6(2): 71-8.

12. Mizumoto, EM, Canniatti-Brazaca, SG, Machado, FMVF. Avaliação química e sensorial de ovos obtidos por diferentes tratamentos. Ciência e Tecnologia de Alimentos. 2008; 28(1): 60-5.

13. Murata, LS, Ariki, J, Machado, CR, Silva, LPG, Rezende, MJM. Effect of oils sources on blood lipid parameters of commercial laying hens. Brazilian Journal of Poultry Science. 2003; 5(3):203-6.

14. Oliveira, TT, Nagem TJ, Silva RR, Albino, LFT, Pinto, AS, Leão, MA. Teores de colesterol e ácidos graxos em ovos de diferentes espécies de aves. Alimentos e Nutrição. 2004; 15(1): 47- 50.

15. Salvador, M, Dalla Santa, PD. Teores de macronutrientes e de colesterol em diferentes tipos de ovos. Boletim do Centro de Pesquisa e Procesamento de Alimentos. 2002; 20(1):133- 40.

16. Santos, MSV. Avaliação do desempenho e qualidade dos ovos de poedeiras comerciais, submetidas às dietas suplementadas com diferentes óleos vegetais. [Tese de Doutorado]. Fortaleza, Ceará: Universidade Federal do Ceará, 2005. 174 pp. 
17. Schoeni, JL; Glass, KA, Mcdermott, JL, Wong, ACL. Growth and penetration of Salmonella enteritidis, Salmonella Heidelberg and Salmonella typhimurium in eggs. 1995; 24(1):385-96.

18. Silva, DJ, Queiroz, AC. Análise de Alimentos (métodos químicos biológicos). Imprensa Universitária da UFV: ed. Viçosa. 2002. 235 pp.

19. Silva, FB, Tanamati, AAC, Stevanato, FB. Composição em ácidos graxos e colesterol na gema de ovos comerciais. PUBVET. 2(12): Disponível em: http://www.pubvet.com.br/artigos_det.asp?artigo=173. Acesso em: 07/10/2010.

20. Silva, FHA. Curso teórico-prático sobre técnicas básicas de avaliação de qualidade do ovo. Piracicaba: ESALQ. s.ed. 2004.

21. Silva, N, Junqueira, VCA, Silveira, NFA. Manual de métodos de análise microbiológica de alimentos. São Paulo: ed. Varela. 1997. 295 pp. 